\title{
Antigen-Specific IgG Antibodies in Stage IV Long-Time Survival Breast Cancer Patients
}

\author{
Mona H. Hansen, Bjørn Østenstad, and Mouldy Sioud \\ Department of Immunology, Molecular Medicine Group, The Norwegian Radium Hospital (M.H.H., M.S.) \\ and the Department of Oncology, Ullevål University Hospital (B.Ø.), Oslo, Norway \\ Accepted January 1, 2001.
}

\begin{abstract}
Background: Profiling the immune responses in patients with cancer is expected to facilitate the design of diagnostic tests and therapeutic vaccines. Such studies usually require the parental antigens. We attempted to profile the immune responses in patients with breast cancer using a peptide phage display selection strategy, which identifies antibody specificities whether or not the antigens are known.

Materials and Methods: A panel of random peptide phage libraries was panned on serum IgG antibodies from breast cancer patients with stage IV, seeking for disease specific IgG epitopes. ELISA, immunoscreening, and Western blotting techniques were the main approaches used.

Results: Phage-displayed peptides were specifically enriched for binding to IgG antibodies from patients with breast cancer. Several peptides have been identified, in particular the SQRIPARIHHFPTSI peptide, which was recognized by IgG antibodies from breast
\end{abstract}

cancer patients, but not from normals $(p<0.0004)$. In patients who responded to the selected peptides, in particular the SQRIPARIHHFPTSI peptide, antibodies against a $66 \mathrm{kDa}$ cellular protein were found. Interestingly, three out of six patients with the strongest immunoreactivity are still alive, with a mean survival time from first recurrence until now of 2553 days. In contrast, all the nonresponders $(n=10)$ are deceased. The mean survival time of these patients was 784 days, whereas the mean survival time of the three deceased responders was 1050 days $(p<0.02)$.

Conclusions. The data provide the first example in which panning of peptide phage display libraries on patient IgG antibodies results in the isolation of breast cancer specific IgG epitopes, some of which correlate with patient survival time. Thus, the identified B-cell epitopes should be of great interest in vaccine development.

Key Words. Breast cancer, phage display, autoantibodies, serological markers.

\section{Introduction}

Several human diseases, including cancer, autoimmune diseases, and infectious diseases, are concerned with the immune responses against self and nonself proteins $(1,2)$. Therefore, defining the specificities of $B$ and $T$ cells in these diseases should facilitate the design of diagnostic tests and vaccines. Unfortunately, the analysis of B- and T-cell epitopes requires structural information about the parental antigens, which is a major limitation if the antigens are not known.

In recent years, peptide phage display libraries have been developed and proved useful tools for the identification of monoclonal antibody specifities, whether or not the parental antigens are known (3-5). This strategy is based on the ability of filamentous bacteriophage to display foreign peptides on their surfaces (6). In contrast to many other molecular methods, the phage display selection strategy relies on the physical link between the displayed

Address correspondence and reprints to: Dr. Mouldy Sioud, The Institute for Cancer Research, Department of Immunology, Molecular Medicine Group, The Norwegian Radium Hospital, Montebello, N-0310 Oslo, Norway. Phone: 4722934563. Fax: 47225007 30. E-mail: mosioud@ulrik.uio.no peptides (phenotype) and the DNA encoding them (genotype). Thus, minigenes encoding for the peptide epitopes with a specific binding affinity can be enriched and selected rapidly. Furthermore, the strategy allows the antibodies to select their own ideal binding peptides. Primarily, we have been interested in investigating the possibility of selecting peptide ligands for antibodies present in patient sera. The rationale is that antibodies from patient sera will bind to the phage containing the peptide epitope initiating the immune response against self or nonself proteins (e.g., virus proteins or tumors). Using phage display approaches, we recently demonstrated that specific humoral immune responses in patients with autoimmune diseases can be traced by the peptide phage display library (7-9). Other groups have also demonstrated the use of the peptide phage display libraries for probing the immune responses in individuals immunized with hepatitis $C$ virus antigens $(10,11)$. Despite this success, the technology has not yet been applied to patients with cancer. Notably, it has been difficult to identify immunogenic antigens capable of inducing immune responses in patients to a threshold required for tumor rejection. In this study, we have investigated whether peptide phage display libraries can trace 
antigen-specific immune responses in patients with breast cancer, with the emphasis on selecting disease specific IgG epitopes.

\section{Materials and Methods}

\section{Sera}

Serum samples from patients with breast cancer with stage-VI lymphoma, prostate cancer, and volunteer blood donors were obtained from Ullevål University Hospital. Sera from patients with osteosarcoma were obtained from The Norwegian Radium Hospital. All sera were aliquoted and stored at $-70^{\circ} \mathrm{C}$ until use. Pooled IgG antibodies from patients and controls were affinity purified using protein G columns according to the manufacturer's instructions (Pharmacia).

\section{Affinity Selection}

The peptide phage libraries were biopanned on patient IgG antibodies as described by Dybwad et al. (7). In brief, $10^{11}$ transduction units from an amplified 15-mer library expressed on pVIII (4) were incubated overnight at $4^{\circ} \mathrm{C}$ with patient IgG, preincubated with the fd phage. After incubation, biotinconjugated anti-human IgG, preincubated with the fd phage, was added to the mixture and incubation was continued for $3 \mathrm{hr}$ at room temperature. Following incubation, streptavidin-coated magnetic beads were added to the mixture and incubation was continued for $30 \mathrm{~min}$. Antibody/phage-binding beads were attracted to a magnet, while unbound phages were removed. Beads were washed 10 times with PBS $/ 0.2 \%$ Tween over a period of $1 \mathrm{hr}$ and streptavidin-binding phages were acid eluted and neutralized by Tris Base. The eluted phages were amplified in E. coli K91 cells and then used for further rounds of selection. The enrichment of specific phage-displayed peptides was monitored by immunoscreening. In the case of the 7- and 12-mer pIII peptide libraries, the eluted phages were amplified in ER 2537 E. coli cells as described by the manufacturer (New England Biolabs).

\section{Immunoscreening}

Serum IgG antibody-binding phages were identified using an immunoscreening technique $(12,13)$. In brief, E. coli K91 cells were infected with the selected phages. Various dilutions of the infected bacteria were plated on NZY agar plates containing tetracycline $(50 \mu \mathrm{g} / \mathrm{mL})$ and IPTG $(1 \mathrm{mM})$ and incubated overnight at $37^{\circ} \mathrm{C}$. Following transfer to the nitrocellulose membranes, the membranes were washed twice with TNT buffer $(10 \mathrm{mM}$ Tris $\mathrm{HCl}$, $150 \mathrm{mM} \mathrm{NaCl}, 0.05 \%$ Tween 20 ) for a total of $30 \mathrm{~min}$ and then blocked for 30 min with $20 \%$ FCS in TNT buffer. After blocking, membranes were incubated with $8 \mu \mathrm{g} / \mathrm{mL}$ pooled IgG in FCS/TNT for $2 \mathrm{hr}$ and then washed once with TNT buffer with $0.1 \%$ BSA and $0.1 \% \mathrm{NP}-40$ for $10 \mathrm{~min}$ and then twice with
TNT buffer with $0.1 \%$ BSA (10 min each). Alkaline phosphatase-conjugated anti-human IgG (1/5000) was added to the membranes and incubated for $2 \mathrm{hr}$. After washing with TNT buffer, the immunoreactive phage clones were detected by BCIP/NBT premixed substrate (Sigma). In the 7- and the 12-mer peptide libraries, random clones from the fourth round of selection were picked up and characterized.

\section{Phage Preparation and Sequencing}

Phages from liquid culture were obtained by polyethylene glycol $6000 / \mathrm{NaCl}$ precipitation as described elsewhere (7). The phages were resuspended in PBS buffer, filtered through $0.45 \mathrm{~mm}$ filter and then stored at $4^{\circ} \mathrm{C}$ until use. For DNA sequencing, phage DNA was prepared and the DNA inserts encoding for the peptides were sequenced by the dideoxy chain termination method. The sequencing reaction was carried out using the Sequenase version II Kit (Amersham).

\section{Enzyme-Linked Immunosorbent Assay (ELISA)}

ELISA experiments were performed as described previously (7). In brief, 96-well microtitre plates were coated overnight at $4^{\circ} \mathrm{C}$ with the purified phages $\left(10^{7} /\right.$ well). After blocking with $0.5 \%$ BSA in PBS buffer for $1 \mathrm{hr}$ at room temperature and subsequent washing, the plates were incubated with sera samples $(1 / 100$ dilution in $\mathrm{PBS} / 0.2 \% \mathrm{BSA} / 0.2 \%$ Tween 20) for $1 \mathrm{hr}$ at $37^{\circ} \mathrm{C}$. After additional washing, plates were incubated with alkaline phosphataseconjugated anti-human IgG (1/5000) for $1 \mathrm{hr}$ at $37^{\circ} \mathrm{C}$. The immune complexes were detected by adding $p$-nitrophenyl phosphate as substrate. The reactivity of each serum to the phage displaying the SQRIPARIHHFPTSI peptide was obtained by subtracting its reactivity to a phage displaying a random peptide (YLRNVSRVLIQSSSN). A result was considered as positive when the serum reactivity was equal to or greater than 3.5-fold of the mean reactivity of normal individuals.

\section{Competition Experiments}

Various concentration of the phage displaying the SQRIPARIHHFPTSI peptide or the wild-type phage was incubated with each patient serum diluted 1/500 in $\mathrm{PBS} / 0.2 \% \mathrm{BSA} / 0.2 \%$ Tween 20 . After incubation overnight at $4^{\circ} \mathrm{C}$, the mixtures were added to the 96well microtiter plates coated with the phage displaying SQRIPARIHHFPTSI peptide $\left(10^{6}\right.$ TU/well $)$. In the experiments with the synthetic peptides, increasing concentrations of the synthetic peptide or a control peptide were incubated with each patient serum (diluted 1/500), incubated overnight at $4^{\circ} \mathrm{C}$ and then added to the 96-well microtiter plates coated with the phage displaying the SQRIPARIHHFPTSI peptide $\left(10^{6} \mathrm{TU} /\right.$ well $)$. The results are expressed as percentage of the serum binding to the phage without competitor. Competitive ELISA experiments with the other phage-displayed peptides were performed as previously described. 


\section{Western Blotting}

Aliquots of $40 \mu \mathrm{g}$ cell proteins were subjected to electrophoresis in SDS $10 \%$ polyacrylamide gels, followed by protein electrotransfer to nitrocellulose membranes and immunoblotting with patient and normal sera at a dilution of $1 / 1000$. Antibody binding was detected through the application of HRPconjugated anti-human IgG antibodies. Immunoreactive bands were visualized with ECL detection reagents (Amersham).

\section{Cytosolic, Nuclear, and Membrane Protein Preparation}

PMI cells (ATCC) were washed twice with PBS and then resuspended in buffer A $(5 \mathrm{mM}$ Tris $\mathrm{HCl}$ pH 8.8, 0.5 mM EDTA and $75 \mathrm{mM}$ sucrose with proteinase inhibitors) and then sonicated 6 times (20 seconds each). After sonication, the nuclei were pelleted by centrifugation at $2000 \mathrm{rpm}$ for $5 \mathrm{~min}$ and then the supernatant was centrifuged at 30,000 rpm for $30 \mathrm{~min}$. The supernatant from this step was saved as the cytosol fraction. The pellet, which contains the membrane fraction, was washed 4 times with PBS, resuspended in buffer A containing $1 \%$ Triton X-100, and incubated on ice for $10 \mathrm{~min}$. After incubation, the sample was centrifuged at 15,000 rpm for $10 \mathrm{~min}$, and the supernatant was saved as the membrane fraction. The nuclei pellet was resuspended in 10\% NP-40 and then sonicated. Protein concentration was determined using the protein assay kit (BioRad Laboratories, Hercules, CA).

\section{Statistics}

Differences between patients and controls were tested for significance with an unpaired $t$-test.

\section{Results}

\section{Affinity Enrichment of Breast Cancer Patient IgG Antibody-Binding Phages}

The ability to probe specific immune responses in patient sera with peptide phage display libraries (7-9) prompted us to evaluate this novel technology in patients with cancer. In these experiments, a pooled IgG fraction derived from seven breast cancer patients with stage IV was epitope-mapped by a panel of random peptide phage libraries as described in Materials and Methods. After six rounds of affinity enrichment, the immuno reactivity of the selected phages was investigated by an immunoscreening technique. This method allows a direct identification of IgG-binding phages after a transfer to nitrocellulose membrane filters. To test for specificity, pooled IgG fractions from patients with lymphoma $(n=6)$, osteosarcoma $(n=8)$, and normals $(n=7)$ were also tested (Figure lA). A strong reactivity was found with pooled IgG antibodies from breast cancer patients (b), but no significant reactivity was found with IgG antibodies from normals (n), patients with lymphoma (l), or those with osteosarcoma (o). Notably, positive clones are clearly distinguishable from negative clones $(b, a r-$
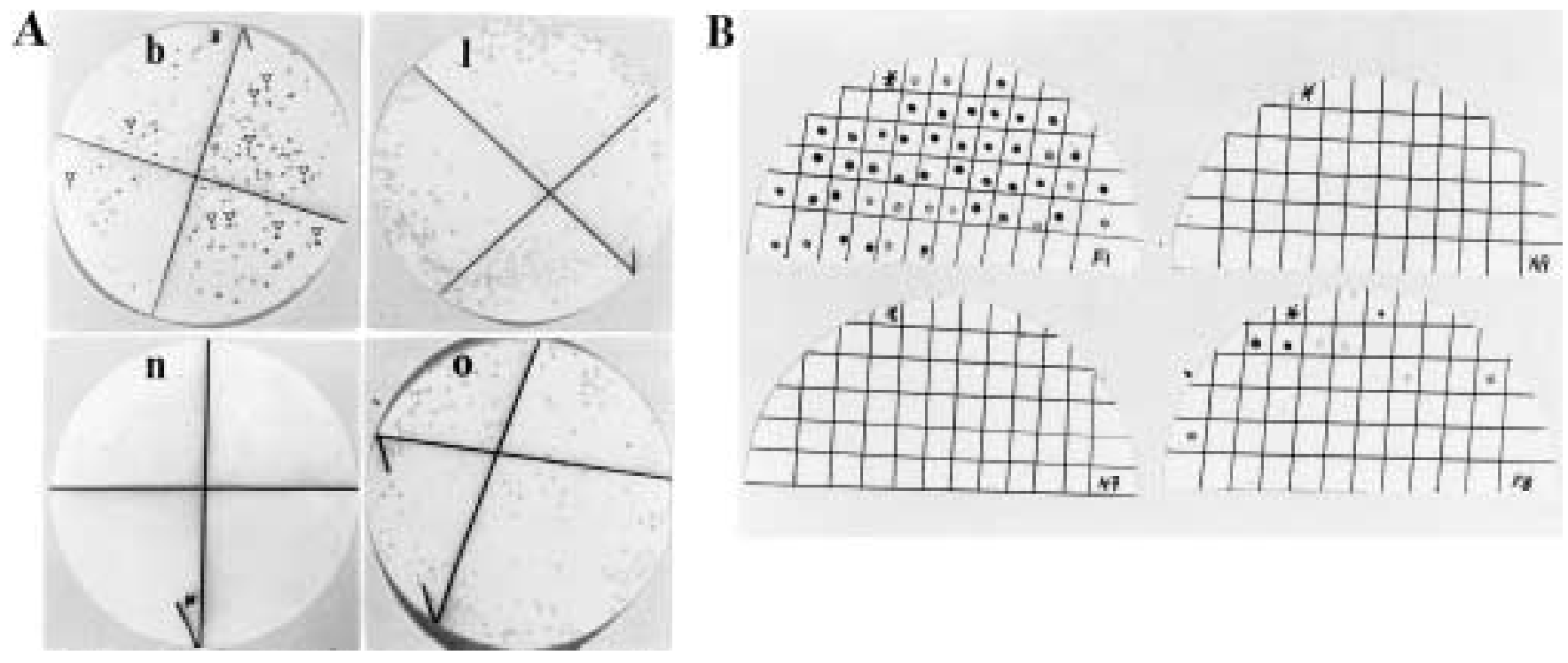

Fig. 1. Immunoreactivity of the selected phages with patients and controls. (A) Reactivity of breast cancer patient sera and controls to random phages derived from the 6th round of selection. Following transfer to nitrocellulose and blocking, the membranes were incubated with $(8 \mu \mathrm{g} / \mathrm{mL})$ pooled IgG fraction from breast cancer patients (b), lymphoma (l), osteosarcoma (o), or normal (n). The use of alkaline phosphatase conjugated anti-human IgG antibodies as described in Materials and Methods detected the immunoreactive phage clones. (B) Reactivity of phage particles with individual serum as detected by immunospot assays. In these experiments purified phage particles $\left(10^{6} \mathrm{TU} / \mathrm{spot}\right)$ were spotted onto nitrocellulose, blocked and then processed as in A. Each serum was used at 1/500 dilution. F1 and F8 are patients with breast cancer. N7 and N9 are normal individuals. 
rowheads), confirming the specificity of the immunoreaction.

To identify the most relevant peptides, phage particles from 63 random positive phage clones were purified and their immunoreactivity to 40 individual serum samples was tested by immunospot assays. A representative example is shown in Figure 1B. A high proportion of breast cancer patients showed strong reactivity to at least one of the selected phages. In our experimental conditions, none of the positive phages reacted with normal serum samples $(n=40)$ or sera from patients with osteosarcoma $(n=10)$. In immunospot assay, some of the selected phage-displayed peptides reacted with at least $15 \%$ of patients with breast cancer.

Structural Characteristic of Peptides Displayed By the IgG Antibody-Selected Phages

To determine the structural characteristic of the peptides displayed by the positive phages from three independent experiments using 15-, 12-, and 7-mer peptide phage display libraries, the DNA sequences encoding for the peptides were determined (Table 1). The sequences were arranged into two groups. The peptides in group A showed different consensus core motifs (bolded amino acids). Group B consisted of peptide with no obvious homology. The phage-displayed peptides which showed reactivity with at least $15 \%$ of breast cancer patients in immunospot assay were found to belong mainly to group A (e.g., SQRIPARIHHFPTSI, TVETPQTAKTAYYAT, SDEQSYSTTRSYYGQ, GSVTQRL). Notably, the SQRIPARIHHFPTSI peptide was selected 46 times.

\section{Humoral Immune Response of Patients and Controls} to the SQRIPARIHHFPTSI Peptide

Although most of the selected B-cell epitopes need further characterization, we have focused on the phage displaying the SQRIPARIHHFPTSI peptide sequence as its reactivity with patient IgG antibodies was the strongest in comparison with the reactivity obtained with other selected phage-displayed peptides. Sera from patients with breast cancer with stage IV $(n=16)$ and normal adults $(n=35)$ were tested by ELISA. The relative reactivity of each patient serum to the phage-displayed SQRIPARIHHFPTSI peptide was obtained by substracting its absorbency to a phage displaying a random peptide (Figure 2A). There were significantly increased peptide IgG antibodies in patients (mean $=0.507$ OD units) compared to normals (mean $=0.156$ OD units) $(p<0.0004)$. Seven out of the 16 patients had antibody levels at least 3.5-fold greater than the mean of the normals. Under our ELISA conditions no significant reactivity was obtained with sera from osteosarcoma $(\mathrm{n}=14)$ and lymphoma patients $(\mathrm{n}=10)$ (data not shown).

To further confirm that the binding seen in ELISA is the result of the interaction of the serum
Table 1. Sequences of phage-displayed peptides obtained from three independent experiments using 15-, 12- and 7mer peptide phage display libraries. The amino acid sequence of each clone is expressed by single-letter abbreviation. Consensus core motifs are shown in bold.

\begin{tabular}{|c|c|c|c|}
\hline $\mathbf{A}$ & Freq $^{a}$. & $\mathbf{B}$ & Freq $^{a}$ \\
\hline GAVAQRL & 1 & & \\
\hline GSVTQRL & 3 & HPEVYLREPVKS & 11 \\
\hline SQRIPARIHHFPTSI & 46 & EFRPLYSSEPGKAHV & 3 \\
\hline \multirow[t]{2}{*}{ SERRIPSNPDTKFAD } & 2 & ASPPKFTSNVKKFSA & 3 \\
\hline & & GVSTPITSKAASSIM & 1 \\
\hline TVETPQTAKTAYYAT & 4 & GSAQSEDIFVVPNML & 1 \\
\hline \multirow[t]{2}{*}{ NVNTPQTVKHPG } & & IIDTPNTTRLRP & 1 \\
\hline & & ESLKEIIVSKLS & 1 \\
\hline YSSSLYY & 4 & DCSAPWIDPACV & 1 \\
\hline WAPPLFRSSLFY & 3 & VPRFIEV & 1 \\
\hline \multirow[t]{2}{*}{ DSSLTSLRNSTR } & 1 & MSTQFFT & 1 \\
\hline & & NPLEALL & 1 \\
\hline WPLKPKL & 5 & ASIDSLR & 2 \\
\hline FPMKPVL & 1 & & \\
\hline GSVTQRL & 3 & & \\
\hline NHEPSVTQVILDRPY & 1 & & \\
\hline SDEQSYSTTRSYYGQ & 1 & & \\
\hline YSTTLSY & 1 & & \\
\hline LTPYHPP & 4 & & \\
\hline APPSPPP & 1 & & \\
\hline HPILWPP & 1 & & \\
\hline
\end{tabular}

${ }^{\text {a }}$ The frequency refers to the number of times each phage was isolated.

IgG antibodies with the peptide displayed by the phage, we performed competition assays. Representative examples are shown in Figure 2 Band C. In competitive ELISA, the binding of the serum IgG was inhibited by the phage itself, whereas no significant effect was obtained with a phage displaying an irrelevant peptide (Figure 2B). The binding of the phage displaying the SQRIPARIHHFPTSI peptide to the patient sera was also inhibited with a synthetic peptide corresponding to the peptide displayed by the phage, but not with an irrelevant peptide (Figure $2 \mathrm{C}$ ), thus confirming the specificity of the IgG binding.

\section{Antibodies to a $66 \mathrm{kDa}$ Cellular Protein in Patients Who Strongly Reacted with the SQRIPARIHHFPTSI Peptide}

The overall evidence presented above suggests that in some patients with breast cancer, specific humoral immune response against tumor cells has been activated. As the first step toward the identification of cellular antigens, protein extracts from a breast cancer cell line (PMI) was prepared, separated by SDS 
Fig. 2. ELISA reactivity of the phage displayed SQRIPARIHHFPTSI peptide with patients and control sera. (A) The reactivity of 16 patients with breast cancer with stage IV $(\diamond)$ and 35 normal individuals $(\bullet)$ toward the phage-displayed SQRIPARIHHFPTSI peptide was tested by ELISA. The absorbency of each serum was obtained by subtracting its absorbency to a phage displaying a random peptide as described in Materials and Methods. (B) Inhibition of the serum antibody to bind the phage-displayed SQRIPARIHHFPTSI peptide by the phage itself or by a phage displaying an irrelevant peptide (Wt phage). (C) Inhibition with synthetic peptides.

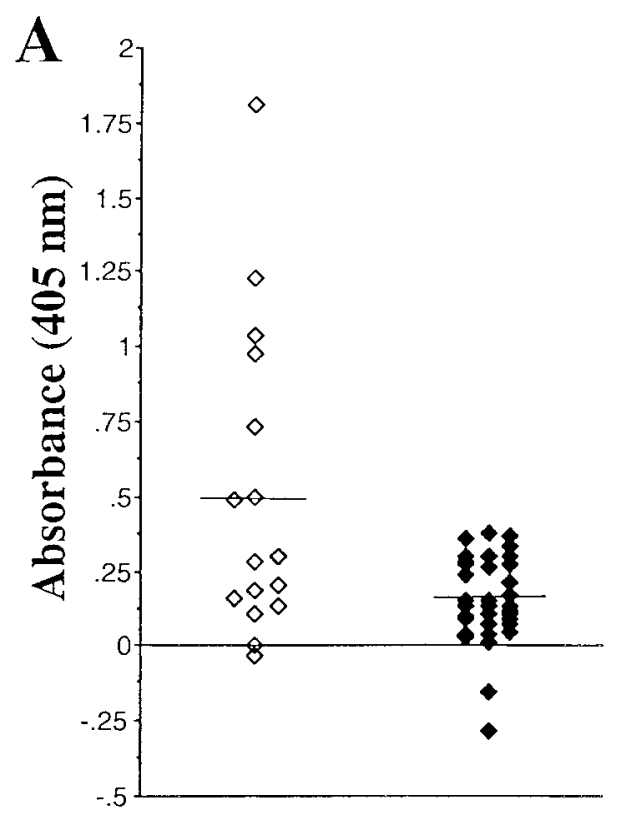

B

Patient 1

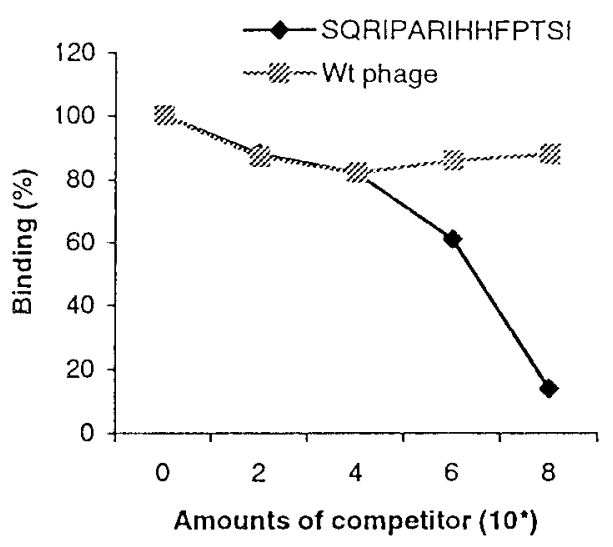

Patient 2

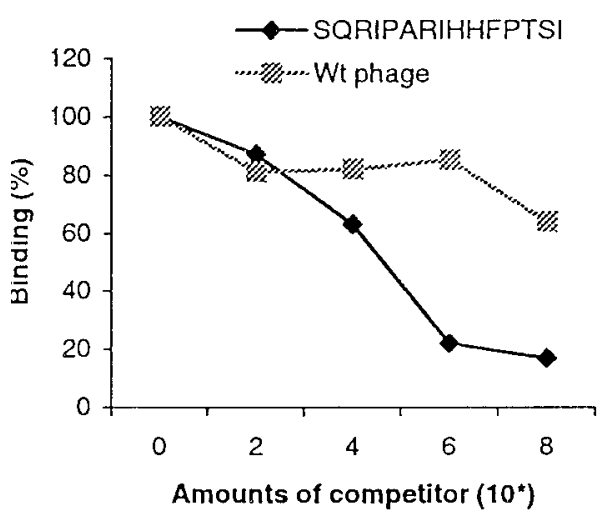

Patient 1

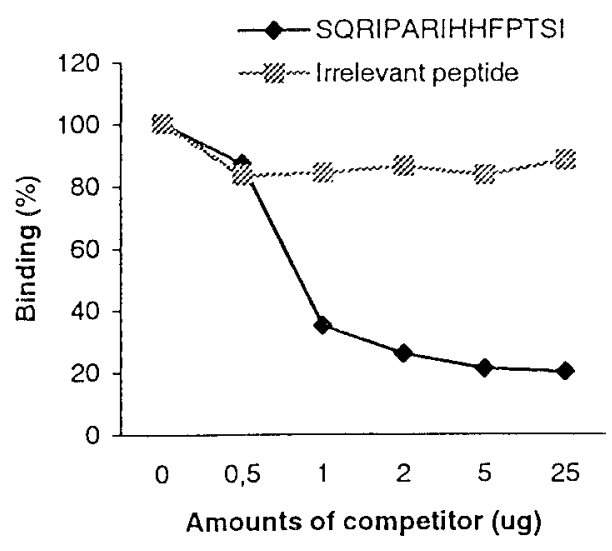

Patient 2

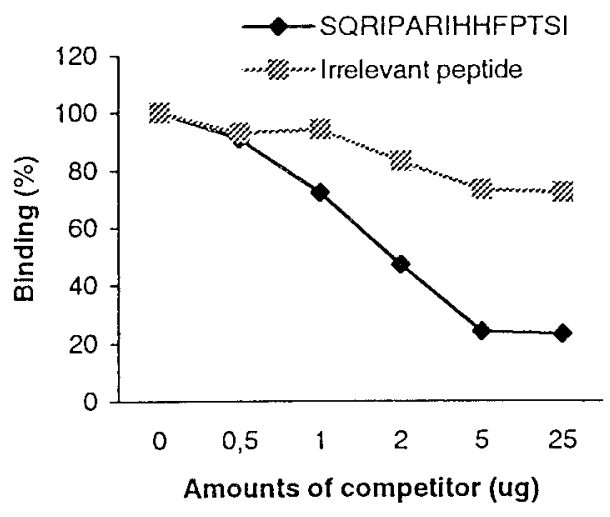




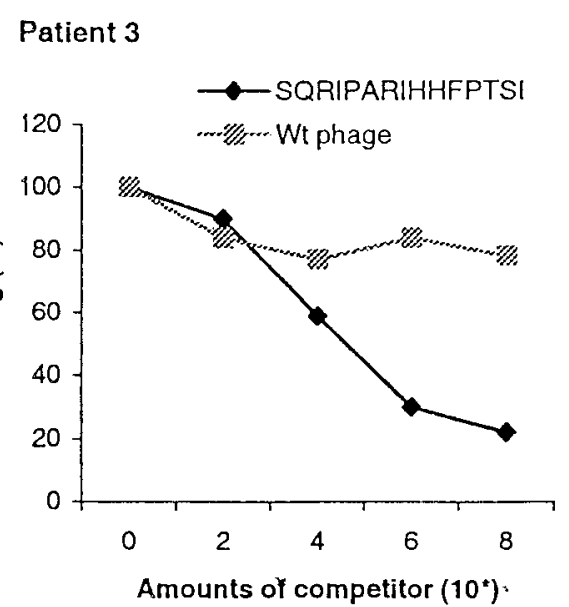

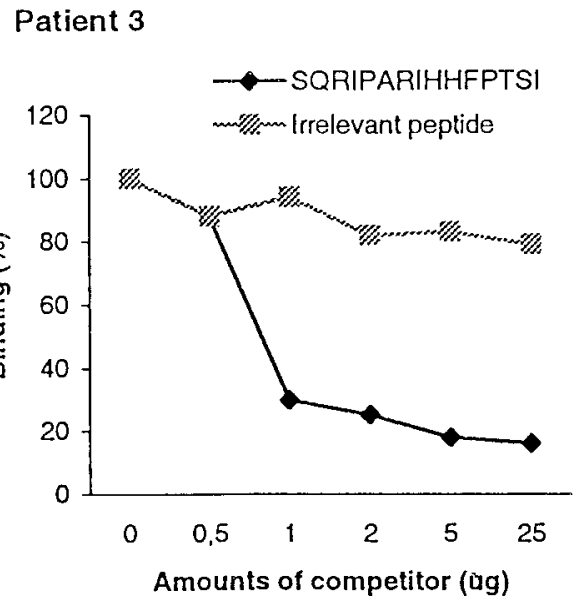

Fig. 2. (Continued)
PAGE, transferred to nitrocellulose membranes, and then incubated with patient sera which strongly reacted with the SQRIPARIHHFPTSI peptide. These patients also reacted with most of the peptides in group A as tested by the immunospot assay. Interestingly, a band with an apparent molecular mass of 66 kDa was strongly recognized by IgG antibodies from only the patients who reacted strongly with the peptide (Fig. 3A, lanes 1-3). No significant reactivity was obtained with IgG serum antibodies from patients who did not react with the peptide (Figure 3B, lanes 1-3), from normals (Figure 3C, lanes $1-3$ ), from patients with prostate cancer (Figure 3D, lanes 1-5), and from patients with osteosarcoma (Figure 3E, lanes 1 and 2). The $66 \mathrm{kDa}$ protein was found to be also expressed by peripheral blood mononuclear cells (Figure 3F, lane 1) and by other cancer cell lines such as the breast cancer cell lines MCF-7 and T47D, and the prostate cancer cell line DU145 (data not shown). Thus, it is more likely to be an autoantigen.

\section{Clinical Significance of the IgG Antibodies to the $66 \mathrm{kDa}$ Protein}

To evaluate the role of the described IgG antibodies against the selected SQRIPARIHHFPTSI peptide and the $66 \mathrm{kDa}$ protein in disease duration, we have analyzed the patients' clinical data. It is important to note that the clinical data of the patients were obtained after the experimental component of this study was completed. Thus, the present study should be considered as a blind investigation. Surprisingly, all patients with stage IV who did not respond to the phage-displayed peptides $(n=10)$, in particular the SQRIPARIHHFPTSI peptide, and to the $66 \mathrm{kDa}$ protein were deceased. The mean survival time of these patients from the first recurrence until the death was 784 days. Three out of six patients with the strongest reactivity are still alive, with a mean survival time from the first recurrence until now of 2553 days. The mean survival time of the three deceased responders

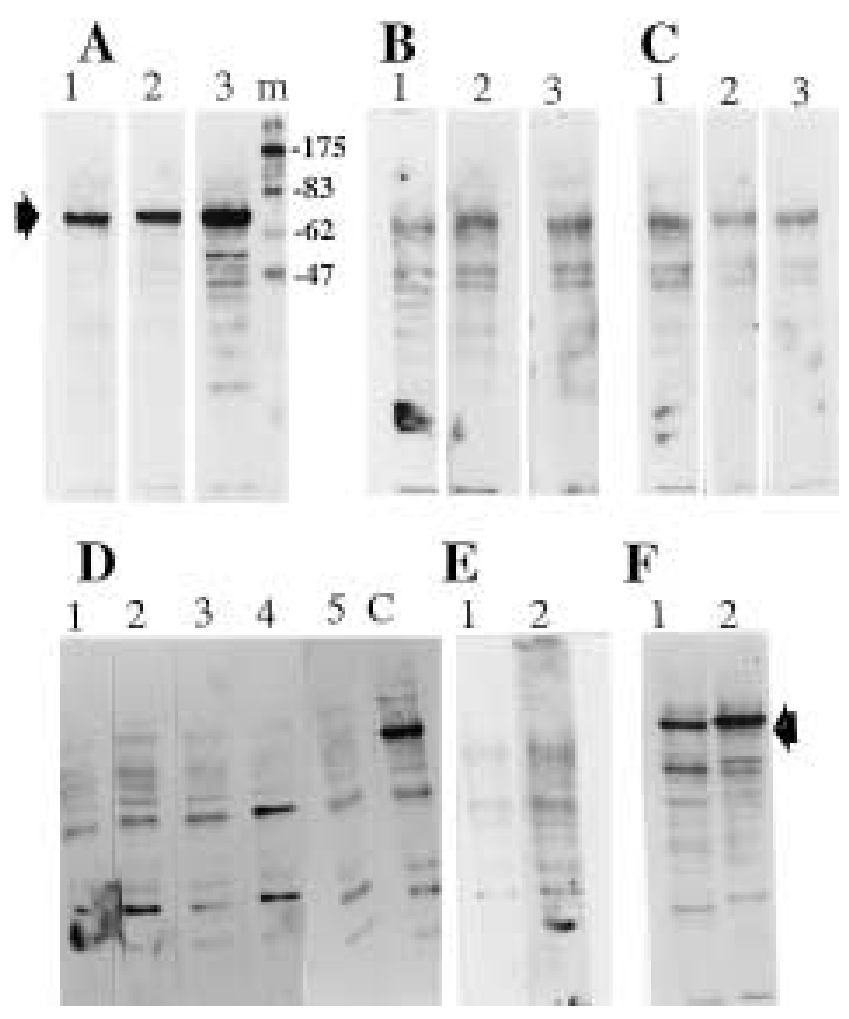

Fig. 3. Western blot analysis of cellular protein extracts from breast cancer cell line PMI. Extracts were separated by $10 \%$ polyacrylamide gel electrophoresis, transferred to nitrocellulose, and incubated with serum from 3 patients with breast cancer who strongly responded to the SQRIPARIHHFPTSI peptide (A, lanes 1-3), 3 patients with breast cancer who did not respond to the peptide (B, lanes $1-3), 3$ normal individuals (C, lanes 1-3 ), 5 patients with prostate cancer (D, lanes 1-5) and 2 patients with osteosarcoma (E, lanes 1 and 2$)$. All sera were used at dilution 1/1000. (F) Western blots of cell extracts prepared from peripheral blood mononuclear cells (lane 1) and from the breast cancer cell line PMI (lane 2). Sera from patient 3 (A) was used. In D sera from patient 3 was used as positive control (C). 
was $\mathbf{1 0 5 0}$ days. There is a difference in survival time between deceased responders and nonresponders $(p<0.02)$.

Following this clinical observation, a second serum sample from a long-time survival patient with 14 years' duration of disease was obtained, and its reactivity was investigated. Western blot analysis of the patient's serum at a dilution of 1:1000 showed positive reaction with the $66 \mathrm{kDa}$ protein at both occasions (Figure 4, lanes $\mathrm{F}$ and $\mathrm{S}$ ). The antibodies are detectable even at dilution 1/5000, suggesting that a very high concentration of high-affinity antibodies were produced in this patient. This patient has responded to most of the selected phage-displayed peptides (Figure 1B, patient Fl). This obervation would indicate that the immune response in this patient is more likely to be directed against different antigens. This is further supported by the fact that phage-displayed peptides with different consensus sequences (Table 1, group A) did not compete with each other in ELISA experiments (e.g., SQRIPARIHHFPTSI VS NHEPSVTQVILDRPY). To address whether the SQRIPARIHHFPTSI peptide and the $66 \mathrm{kDa}$ protein are physically related, we have investigated whether affinity purified SQRIPARIHHFPTSI peptide antibodies would react with the $66 \mathrm{kDa}$ protein. No significant reactivity was obtained with the purified antibodies, indicating that the antigen containing the peptide is not the $66 \mathrm{kDa}$ protein. However, it is worth noting that the anti-66 kDa antibodies were found only in patients with high IgG titer against the peptide.

To determine the cellular localization of the protein, cellular fractions containing the cytosolic, membrane and nuclear proteins were prepared from PMI cells and then analyzed by Western blotting. The $66 \mathrm{kDa}$ protein was found to be associated with the cytosolic fraction (Figure 4, lane C).

\section{Discussion}

The current study shows that peptide phage display libraries can be used to trace specific immune responses in patients with breast cancer whether or

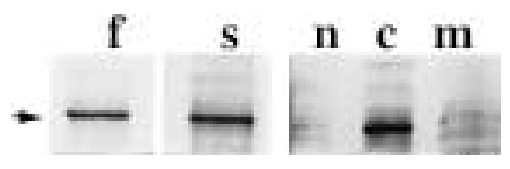

Fig. 4. Western blot analysis using a patient serum obtained at the second occasion and cellular localization of the $66 \mathrm{kDa}$ protein. Protein extracts were separated by $10 \%$ polyacrylamide gel electrophoresis, transferred to nitrocellulose and then incubated with patient serum obtained at the first (f) and the second (s) occasion. Both sera were used at a dilution of $1 / 1000$. To determine the cellular localization of the $66 \mathrm{kDa}$ protein, subcellular fractionations were prepared as described in Materials and Methods and analyzed by Western blotting. N, nuclear proteins; c, cytosolic proteins; and m, membrane proteins. not the parental antigens are known. Indeed, IgG antibodies to the selected peptides were found in patients with breast cancer and not in patients with lymphoma, osteosarcoma or normal individuals (Figure 1, A and B). Therefore, the selected peptides should constitute a valuable source for the development of serological markers. Three patients with high titer IgG antibodies against the SQRIPARIHHFPTSI peptide are still alive despite the stage IV of the disease, indicating that high-titer antibody responses in some patients is indeed translated into an improved outcome.

As shown in Table 1, a variety of peptide core motifs have been selected. Most important, similar, if not identical, peptide sequences were selected from three phage libraries displaying peptides of different lengths. The selection of such core motifs from different libraries is consistent with the presence of specific immune response in the pooled IgG fraction from patients with breast cancer (14). Indeed, the presence of specific IgG antibodies against, for example, the SQRIPARIHHFPTSI peptide, was consistent with the competition phage ELISA (Figure 2, B and C). Most of the other phagedisplayed peptides in group A also reacted specifically with serum from individual patients. In this respect, $32 \%$ and $27 \%$ of breast cancer patients reacted with the phage displaying the TVETPQTAKTAYYAT or NHEPSVTQVILDRPY, respectively. In contrast, no significant reactivity was found with normal sera. Thus, phage display-based approaches will undoubtedly be important for probing immune responses in patients with cancer.

The portion of an antigen molecule that is specifically recognized by an antibody combining site (paratope) is generally referred to as an antigenic determinant (epitope). Protein epitopes have been divided into two major categories (15). Conformational epitopes involve residues widely spaced in the primary sequence but brought into spatial proximity by protein folding. These epitopes are absent in denatured proteins. Continuous epitopes consist of residues adjacent in the primary sequences, and are therefore detectable in denatured protein. The immunizing epitopes may not represent the optimal binding motif for the antibodies. Indeed, high affinity mimotopes with no apparent homology to the immunogen have been described (4). The phage display strategy allows the antibodies to select their own ideal peptides. Therefore, some of the selected peptides may not be homologous in sequence to the parental immunogens, yet they perfectly mimic the immunogen structures. These mimic peptides (mimotopes) are extremely useful as diagnostic and prognostic tools as well as a novel form of vaccine $(16,17)$, especially when protective immunity can not be obtained with the parental antigens. In addition, linear epitopes could be valuable leads for the identification of the parental immunogens (9). In this respect, homology search with the SQRIPARIH- 
HFPTSI peptide core motif (SQRIP) indicated that it is present in human CMV coat protein, suggesting a possible molecular mimicry with human protein(s). CMV infection has been implicated in breast cancer (18). However, two patients who responded to the peptide were found to be CMV negative. Thus, the immune response to the SQRIP core motif peptide is not CMV-related, at least not in these patients. It is worth noting that the phage display strategy identifies both linear and conformational epitopes. Therefore, sequences identified by homology search should be considered only as leads that need further investigation. Furthermore, the induction of the immune response against the selected peptides is likely to be unrelated to chemotherapy as evidenced by one of the responders, who is still alive but did not receive chemotherapy.

Spontaneous regressions of human tumors have been reported in some types of cancer, including breast cancer (19). This process is more likely to be the result of the interaction of the immune system with tumor cells. Therefore, in some patients, the immune system seems to be activated against tumor cells. Immune responses against some cellular proteins such as Ras, p53 and heat shock proteins have been described in patients with cancer (20). In the present study, high IgG antibody titers against a $66 \mathrm{kDa}$ cellular protein were found in patients who strongly reacted with group A peptides (Table 1), in particular, the SQRIPARIHHFPTSI peptide. In one patient, the $66 \mathrm{kDa}$ antibodies are detectable even at serum dilution 1/5000. Notably, no physical link was found between the SQRIPARIHHFPTSI peptide and the $66 \mathrm{kDa}$ protein. Thus, it appears that the patients who developed a strong immune response towards the antigen-containing peptides also developed immune response against the $66 \mathrm{kDa}$ protein. This observation is not surprising, as immune responses against different antigens have been described in patients with cancer. Indeed, sera from melanoma patients reacted with both NY-ESO-1 and MAGE- 1 antigens (21). It is worth noting that under some unknown conditions, the immune response to self has the potential to spread in an intra- and intermolecular fashion (22). This phenomenon, known as "epitope spreading," is expected to increase the power of the immune response toward target tissues such as tumors. Therefore, it is perhaps not surprising that the patients who strongly responded to most of the selected peptides in group A (Table 1) and the $66 \mathrm{kDa}$ protein had the longest survival. In particular patient $\mathrm{fl}$ who is still doing well.

The presence of IgG antibodies to the $66 \mathrm{kDa}$ cellular protein suggests the occurrence of an autoimmune process in these patients. Notably the identified $66 \mathrm{kDa}$ protein was found to be a cytosolic protein. Intracellular antigens are not normally accesible to antibodies. However, tumor necrosis could be responsible for the release of cytoplasmic proteins that may subsequently activate the host im- mune system (23). Humoral and cellular responses against intracellular proteins such as p53 and Ras have been described in patients with cancer (20). Whatever the mechanism that initiated the immune response, the anti-66 $\mathrm{kDa}$ antibodies do not seem to cause other clinical features. This observation, together with the expression of the protein in PBMC cells, suggest that the described antibodies are not pathogenic. From an immunological standpoint, both $\mathrm{B}$ - and T-cell responses may help to produce antitumor response in the long-time survival patients. In addition to being markers for screening, antibodies also have the potential to control tumor growth by antibody-dependent cell mediated cytotoxicity. Notably, the anti-66 kDa antibodies are IgG which predicts the coexistence of helper T-cell (24).

Regarding vaccines, intracellular and membranebound proteins have been used (25). In the case of intracellular antigens, T-cell response against tumors has been elicited by immunization with Ras peptides in animal models for cancers (26). In addition, immunization with MHC class I restricted Ras peptides generated specific T-cell response in patients with pancreatic cancer (27). Notably, tumor-infiltrating lymphocytes have been found in many tumors. These cells can be primed by intracellular proteins released during tumor necrosis. After specific B- and T-cell activation, however, it remains to be determined whether the immune response spreads to other peptide epitopes on the same protein and to different epitopes on different tumor proteins. In principle, this concept of determinant spreading (22) should enhance the eradication of tumors. Many factors, including the nature of the initial antigen and perhaps the extent of the "danger" (28) may control the activation of this process. The immune response in the responders who are still alive, in particular patient $\mathrm{fl}$, seems to be directed against more than one antigen. Therefore, the identification of immunogenic antigens that can initiate the determinant spreading process should facilitate the design of therapeutic cancer vaccines.

Some studies have evaluated the immunity in breast cancer patients to defined antigens (29-36). However, none of the described antigens appears to be the $66 \mathrm{kDa}$ protein. Notably, antibodies to purified human heat shock protein hsp 90 have been detected by ELISA in $37 \%$ of patients with breast cancer $(29,30)$. The presence of these antibodies was found to correlate with patient survival and metastatic occurrence $(30,31)$. Between $10 \%$ and $25 \%$ of patients with breast cancer have been found to have antibodies against the p53 protein (32). However, their clinical significance was not established (33). Antibodies to epithelial mucin have also been detected in patients with breast cancer and found to protect against disease progression (34). High-titer antibodies against Her-2/neu protein were detected in patients with early-stage breast cancer (35) and antibodies to a $128 \mathrm{kDa}$ synaptic protein were found 
in three women with the stiff-man syndrome and breast cancer (36).

Why do some patients develop such high titers of anti-66 kDa protein IgG antibodies while others do not? Two major sources may account for the initiation of the immune response in these patients. One form of induction of the immune response would be molecular mimicry. Indeed, a similarity between, for example, virus proteins and endogenous protein may lead to autoreactive immune response at the level of antibodies and T cells (37-41). The second form is endogenous immunization. In this case, we can speculate that tolerance against the $66 \mathrm{kDa}$ and the selected peptide-containing antigens is broken in some patients with breast cancer. Notably, it is becoming clear that many antigenic determinants on self-proteins have not induced self-tolerance (42), and these peptide determinants can be target structures for autoimmune diseases and could provide potential targets for immune response against tumors. Thus, understanding the mechamisms that modulate the immune response against these peptide determinants (cryptic epitopes) in patients with cancer may reveal what needs to be overcome in the cancer patients to allow the killing of tumors. We believe that in the long-time survival patients, in particular patient $\mathrm{fl}$, an anti-tumor autoimmunity is likely to be responsible for the improved outcome. We are in the process of validating our findings in a prospective study of breast cancer patients that analyses the level of IgG antibody against the selected peptides and the $66 \mathrm{kDa}$ protein in serum samples taken at various time points (e.g., diagnosis) and relates the presence of these antibodies to the outcome of the disease.

In conclusion, our data identify specific IgG antibodies in breast cancer patients towards the selected peptides, in particular the SQRIPARIHHFPTSI peptide. High titers of IgG antibodies against a $66 \mathrm{kDa}$ protein was found in some patients who responded to the peptide and have long survival time. This observation should have therapeutic potential. The identity of the $66 \mathrm{kDa}$ protein is under investigation in our laboratory. Finally, the demonstration that specific immune responses in patients with cancer can be traced by phage display should facilitate the study of tumor immunology.

\section{Acknowledgements}

This work is supported in part by the Norwegian Foundation for Health and Rehabilitation to Dr. Sioud. We thank Dr. Øyvind Melien and Anne Dybwad for critical reading of the manuscript. We are indebted to the treating physicians and the patients at Ulleval University Hospital for their cooperation.

\section{References}

1. Houghton AN. (1994) Cancer antigens: immune recognition of self and altered self. J. Exp. Med. 180: 1-4.
2. Sahin U, Tureci O, Schmitt H, Cochlovius B, Johannes T, Schmits R, Stenner F, Luo G, Schobert I, Pfreundschuh M. (1995) Human neoplasms elicit multiple specific immune responses in the autologous host. Proc. Natl. Acad. Sci. USA 92: 11810-11813.

3. Scott JK, Smith GP. (1990) Searching for peptide ligands with an epitope library. Science 249: 386-390.

4. Bonnycastle LLC, Mehroke JS, Rashed M, Gong X, Scott JK. (1996) Probing the basis of antibody reactivity with a panel of constrained peptide libraries displayed by filamentous phage. J. Mol. Biol. 258: 747-762.

5. Stephen CW, Lane DP. (1992) Mutant conformation of p53. Precise epitope mapping, a filamentous phage epitope library. J. Mol. Biol. 225: 577-583.

6. Smith GP. (1985) Filamentous fusion phage: Novel expression vectors that display cloned antigens on the virion surface. Science 228: 1315-1316,

7. Dybwad A, Førre Ø, Kjeldsen-Kragh J, Natvig JB, Sioud M. (1993) Identification of new B cell epitopes in the sera of rheumatoid arthritis patients using a random nanopeptide phage library. Eur J. Immunol. 23: 3189-3193.

8. Sioud M, Dybwad A, Jespersen L, Suleyman S, Natvig JB, Førre Ø. (1994) Characterization of naturally occurring autoantibodies against tumour necrosis factor-alpha (TNF-a): In vitro function and precise epitope mapping by phage epitope library. Clin. Exp. Immunol. 98: 520-525.

9. Dybwad A, Bogen B, Natvig JB, Førre Ø, Sioud M. (1995) Peptide phage libraries can be an efficient tool for identifying antibody ligands for polyclonal antisera. Clin. Exp. Immunol. 102: 438-442.

10. Folgori A, Tafi R, Meola A, Felici F, Galfre G, Cortese R, Monaci P, Nicosia A. (1994) A general strategy to identify mimotopes of pathological antigens using only random peptide libraries and human sera. EMBO J. 13: 2236-2243.

11. Bartoli F, Nuzzo M, Urbanelli L, Bellintani F, Prezzi C, Cortese R, Monaci P. (1998) DNA-based selection and screening of peptide ligands. Nature Biotech 16: 1068-1073.

12. Sambrook J, Fritsch EF, Maniatis T (eds.) “Molecular Cloning: A Laboratory Manual." Cold Spring Harbor, NY: Cold Spring Harbor Laboratory Press, 1982.

13. Christian RB, Zuckermann RN, Kerr JM, Wang L, Malcolm BA. (1992) Simplified methods for construction, assessment and rapid screening of peptide libraries in bacteriophage. J. Mol. Biol. 227: 711-718.

14. Felici F, Galfre G, Luzzago A, Monaci P, Nicosia A, Cortese R. (1996) Phage-displayed peptides as tools for characterization of human sera. Methods Enzymol. 267: 116-129.

15. Berzofsky JA. (1985) Intrinsic and extrinsic factors in protein antigenic structure. Science 229: 932-940.

16. Meola A, Delmastro P, Monaci P, Luzzago A, Nicosia A, Felici F, Cortese R, Galfre G. (1995) Derivation of vaccines from mimotopes: immunogenic properties of human hepatitis b virus surface antigen mimotopes displayed on filamentous phage. J. Immunol. 154: 3162-3172.

17. Apostololoulos V, Sandrin MS, McKenzie IF. (1999) Mimics and cross reactions of relevance to tumour immunotherapy. Vaccine 18: 268-275.

18. Richardson A. (1997) Is breast cancer caused by late exposure to a common virus? Med. Hypotheses 48: 491-497.

19. Balch CM, Houghton AN, Milton GW, Soong SJ. Cutaneous melanoma. Philadelphia: Lippincott, 1992.

20. Disis ML, Cheever MA. (1996) Oncogenic proteins as tumor antigens. Curr. Opin. Immunol. 8: 637-642.

21. Stockert E, Jager E, Chen Y-T, Scanlan MJ, Gout I, Karbach J, Arand M, Knuth A, Old LJ. (1998) A survey of the humoral immune responses of cancer patients to a panel of human tumor antigens. J. Exp. Med. 187: 1349-1354.

22. Kaufman DL, Clare-Salzler M, Tian J, Forsthuber T, Ting GSP, Robinson P, Atkinson MA, Sercarz EE, Tobin AJ, Lehmann PV. (1993) Spontaneous loss of T-cell tolerance to glutamic acid decarboxylase in murine insulin-dependent diabetes. Nature 366: 69-72.

23. Christian CL, Elkon KB. (1986) Autoantibodies to intracellu- 
lar proteins: clinical and biological significance. Am. J. Med. 80: $53-61$.

24. Stevens TL, Bossie A, Sanders VM, Fernandez-Botram R, Coffman LR, Mosmann RT, Vitetta ES. (1988) Regulation of antibody isotype secretion by subsets of antigen-specific helper T cells. Nature 334: 255.

25. Knuth A, Wolfel T, Meyer zum, Buschenfelde KH. (1991) Cellular and humoral responses against cancer: implication for cancer vaccines. Curr. Opin. Immunol. 3: 659-664.

26. Fenton RG, Keller CJ, Hanna N, Taud DD. (1995) Induction of T-cell immunity against Ras oncoprotein by soluble protein or Ras-expressing E. Coli. J. Natl. Cancer Inst. 87:1853-1861.

27. Gjertsen MK, Bakka A, Breivik J, Saeterdal I, Solheim BG, Soreide O, Thorsby E, Gaudernack G. (1995) Vaccination with mutant Ras peptides and induction of T-cell responsiveness in pancreatic carcinoma patients carrying the corresponding Ras mutation. Lancet 346: 1399-1400.

28. Matzinger P. (1994) Tolerance, danger, and the extended family. Annu. Rev. Immunol. 12: 991-1045.

29. Conroy SE, Latchman DS. (1996) Do heat shock proteins have a role in breast cancer? Brit. J. Cancer 74: 717-721.

30. Conroy SE, Gibson SL, Brunstrom G, Isenberg D, Luqmani Y, Latchman DS. (1995) Autoantibodies to the 90kD heat shock protein in sera of breast cancer patients. Lancet 345: 126.

31. Conroy SE, Sasieni PD, Fentiman I, Latchman DS. (1998) Autoantibodies to the $90 \mathrm{kD}$ heat shock protein and poor survival in breast cancer patients. Eur. J. Cancer 34: 942-943.

32. Crawford LV, Pim DC, Bulbrook RD. (1982) Detection of antibodies against the cellular protein P53 in sera from patients with breast cancer. Int. J. Cancer 30: 403-408.

33. Vojtesek B, Kovarik J, Dolezalova H, Nenutil R, Havlis P,
Brentani RR, Lane DP. (1995) Absence of P53 autoantibodies in a significant proportion of breast cancer patients. Br. J. Cancer 71: 1253-1256.

34. von Mensdorff-Pouilly S, Gourevitch MM, Kenemans P, Verstraete A, Litvinov SV, van Kamp GJ, Meijer S, Vermorken J, Hilgers J. (1996) Humoral immune response to polymorphic epithelial mucin 1 in patients with benign and malignant breast tumours. Eur. J. Cancer 32: 1325-1331.

35. Disis ML, Pupa SM, Gralow JR, Dittadi R, Menard S, Cheever MA. (1997) High-titer HER-2/neu protein specific antibody can be detected in patients with early-stage breast cancer. J. Clin. Oncol. 15: 3363-3367.

36. Folli F, Solimena M, Cofiell R, Austoni M, Tallini G, Fassetta G, Bates D, Cartlidge N, Bottazzo GF, Piccolo G. (1993) Autoantibodies to a $128 \mathrm{kDa}$ synaptic protein in three women with the stiff-man syndrome and breast cancer. N. Engl. J. Med. 238: 546-551.

37. Oldstone MB. (1987) Molecular mimicry and autoimmune disease. Cell 50: 819-820.

38. von Herrath MG, Oldstone MB. (1996) Virus-induced autoimmune disease. Curr. Opin. Immunol. 8: 878-885.

39. Davies JM. (1997) Molecular mimicry: can epitope mimicry induce autoimmune disease? Immunol. Cell Biol. 75: 113-126.

40. Wucherpfennig KW, Strominger JL. (1995) Molecular mimicry in T-cell-mediated autoimmunity: viral peptides activate human $\mathrm{T}$ cell clones specific for myelin basic protein. Cell 80: 695-705.

41. Talbot PJ, Paquette JS, Ciurli C, Antel JP, Ouellet F. (1996) Myelin basic protein and human coronavirus 229E crossreactive T cells in multiple sclerosis. Ann. Neurol. 39: 233-240.

42. Lanzavecchia A. (1995) How can cryptic epitopes trigger autoimmunity? J. Exp. Med. 181: 1945-1948. 